\title{
Room Temperature Plastic Flow Localization in a Mn-Alloyed Austenitic Steel
}

This paper is dedicated to Prof. Evangelista in the occasion of his $70^{\text {th }}$ birthday
D. Firrao ${ }^{1}$, P. Matteis ${ }^{1}$, G.M.M. Mortarino¹, P. Russo Spena ${ }^{1}$, G. Scavino ${ }^{1}$, F. D'Aiuto $^{2}$

${ }^{1}$ Department of Materials Science and Chemical Engineering, Politecnico di Torino, Torino, Italy

${ }^{2}$ Fiat Auto Engineering \& Design, Torino, Italy

\begin{abstract}
A fully austenitic steel containing $0.5 \mathrm{wt} . \% \mathrm{C}$ and $22 \mathrm{wt} . \% \mathrm{Mn}$ was recently proposed for the fabrication of automotive body structures by room-temperature sheet forming, the goal being weight reduction and better crash performance owing to its much higher yield stress and elongation (as compared to presently employed ferritic and multiphase steels). Full-thickness tensile specimens, cut from as-produced sheets, were polished and tested at different strain rates, and the macroscopic surface relief eventually induced by the plastic deformation was recorded with a video camera. Between 0.3 and 0.4 true strain, successive macroscopic deformation bands (forming about $45^{\circ}$ angle with the tensile axis and involving the full specimen width) travel along the specimen, a new one being nucleated as the previous reaches one of the specimen heads, whereas the gage displacement vs. stress curve shows a series of steps, each corresponding to the transit of a band through the gage length, and the cross-head displacement vs. stress curve shows isolated stress peaks, each immediately preceding the nucleation of a new band. Afterwards, and up to rupture, a series of stationary deformation bands appear, most being immediately adjacent to the preceding ones, with the stress vs. strain curve showing a series of serrations with large stress drops. As the strain rate is increased from 0.0004 to $0.4 \mathrm{~s}^{-1}$, the overall flow stress slightly decreases and the mentioned plastic localization phenomena become less evident.
\end{abstract}

\section{Introduction}

Austenitic steels are widely used in many applications because of excellent combination of strength and ductility and corrosion resistance. In the automotive industry, structural components must display high strength, good formability and excellent energy absorption capability in order to reduce section thickness (for vehicle weight reduction, fuel saving and emission control), as well as to facilitate drawing of complex shapes and to provide enhanced crash performance, respectively.

High manganese steels have a remarkable combination of strength and ductility (better than traditional automotive steels such as ferritic deep-drawing steels, high-strength low-alloy, and multiphase steels), due to extensive twins formation under mechanical load, known as the TWIP effect (TWinning Induced Plasticity). These steels satisfy the abovementioned requirements for automotive industries [1].

TWIP steel tensile properties [2,3,4] and work-hardening behaviour [5,6] have already been studied, without an in depth study of the overall plastic behaviour. Thereby we focused on the mechanism of plastic deformation of a batch produced TWIP steel, with the composition reported in Tab. I.

\begin{tabular}{|c|c|c|c|c|c|c|c|c|}
\hline Steel & $\begin{array}{c}\mathrm{C} \\
{[\%]}\end{array}$ & $\begin{array}{c}\mathrm{Mn} \\
{[\%]}\end{array}$ & $\begin{array}{c}\mathrm{Mo} \\
{[\%]}\end{array}$ & $\begin{array}{c}\mathrm{V} \\
{[\%]}\end{array}$ & $\begin{array}{c}\mathrm{Cr} \\
{[\%]}\end{array}$ & $\begin{array}{c}\mathrm{P} \\
{[\%]}\end{array}$ & $\begin{array}{c}\mathrm{S} \\
{[\%]}\end{array}$ & {$[\%]$} \\
\hline CTWIP & 0.50 & 22.4 & 0.7 & 0.22 & 0.16 & 0.13 & 0.025 & $<0.001$ \\
\hline
\end{tabular}

Table 1. Chemical composition of the CTWIP steel (\%wt.). 
In the high manganese and carbon TWIP (CTWIP) steel examined, manganese is the most important alloy element; it stabilizes a metasTab. austenitic matrix at room temperature (with lower and more sTab. cost respect to Ni), impeding the formation of the ferrite and manganese carbides foreseeable by the Fe-C-Mn equilibrium ternary phase diagram. Another important function of manganese is to reduce the austenite stacking fault energy, favoring the TWIP effect during deformation [6]. Carbon is necessary to increment yield and tensile strength.

To obtain useful results for forming operations, several tensile tests were performed at different cross-head speed from low to medium deformation rates.

\section{Experimental Procedures}

Full-thickness tensile specimens $(1.5 \times 20 \mathrm{~mm}$ cross section and $80 \mathrm{~mm}$ gage length), cut from asproduced sheets, were tested at 4 different strain rates, operating a servohydraulic testing system under cross-head displacement control: $0.06,0.5,5$ and $40 \mathrm{~mm} / \mathrm{s}$; as a consequence, during each test, the strain rate varied in the $0.0003-0.0005 \mathrm{~s}^{-1}, 0.003-0.005 \mathrm{~s}^{-1}, 0.03-0.05 \mathrm{~s}^{-1}$, and $0.27-0.57 \mathrm{~s}^{-1}$ ranges, respectively.

All tensile samples were mirror polished prior to the tests in order to record, by using a video camera, the development of macroscopic surface relief possibly induced by the plastic deformation, and to examine thereafter the deformed microstructure by means of SEM microscopy, without further preparation.

Sheet samples, cut adjacent to the tensile specimens, were used for Vickers macro- and microhardness characterization of the original material. The latter measurements were carried out along the cross section of the specimens in order to evaluate the occurrence of any mechanical inhomogeneity arising from the previous production and sampling procedures. All hardness values are averages of at least three indentations.

The microstructural characterization was carried out by optical microscopy on specimens that were cut from the as-received sheet and from tensile samples already tested. The microstructures were examined after a Picral etch. The austenitic average grain size was determined by using the circular intercept method [7].

X-ray diffraction analyses were performed before and after the tensile tests, in order to detect possible second phases and deformation-induced martensitic transformations. A SEM analysis was also performed on the tensile samples, on the fracture surfaces.

\section{Results}

The microstructure of the as-received CTWIP sheet is completely austenitic and the average grain size is $3 \mu \mathrm{m}$ (mean of 85 intercepts), rather homogeneous (Fig. 1). The occurrence of other phases or precipitates was not detected, neither by the optical metallographic analysis nor by the X-ray diffraction analysis (described below), which heads to the conclusion that the carbon and the other alloy elements are completely solubilized in the austenitic matrix.

All the as-received samples have a similar Vickers hardness, around $290 \mathrm{HV}_{100}$. No significant micro-hardness difference was detected on the sheet cross section; thus it can be concluded that the previous production and sampling procedures have not introduced sensible mechanical inhomogeneity in the sheet thickness. 


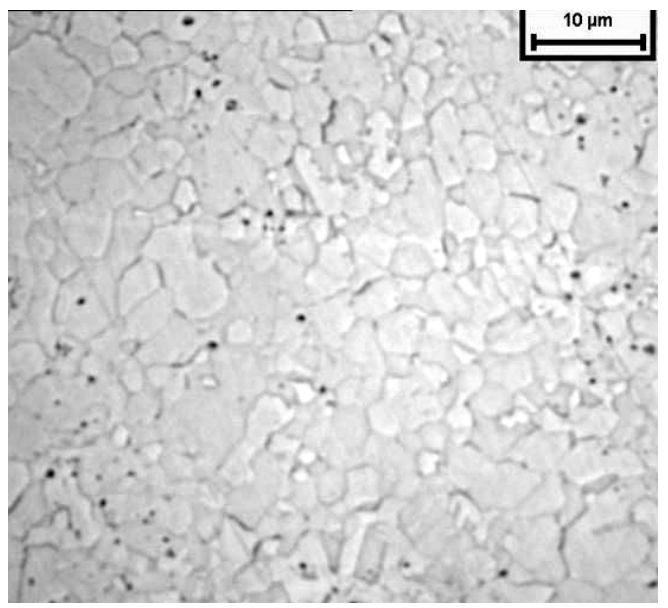

Fig. 1. Microstructure of CTWIP. Austenite (Picral etch).

The tensile properties of the CTWIP steel are listed in Tab. II.

\begin{tabular}{|c|c|c|c|c|c|c|}
\hline $\begin{array}{c}\text { Cross-head } \\
\text { speed }\end{array}$ & $\begin{array}{c}\text { Strain rate } \\
\text { (average) }\end{array}$ & $\begin{array}{c}\text { Yield } \\
\text { strength }\end{array}$ & $\begin{array}{c}\text { Tensile } \\
\text { strength }\end{array}$ & $\begin{array}{c}\text { Uniform } \\
\text { elongation }\end{array}$ & $\begin{array}{c}\text { Strain hardening } \\
\text { exponent }\end{array}$ & E $_{\text {PL }}{ }^{*}$ \\
\hline$[\mathrm{mm} / \mathrm{s}]$ & {$\left[\mathrm{s}^{-1}\right]$} & {$[\mathrm{MPa}]$} & {$[\mathrm{MPa}]$} & $\%$ & - & - \\
\hline 0.06 & 0.0004 & 555 & 1180 & 65 & 0.35 & 0.2 \\
\hline 0.5 & 0.004 & 540 & 1125 & 70 & 0.37 & 0.33 \\
\hline 5 & 0.04 & 552 & 1100 & 72 & 0.37 & 0.52 \\
\hline 40 & 0.4 & 557 & 1065 & 56 & 0.34 & $\begin{array}{c}\text { Not } \\
\text { observed }\end{array}$ \\
\hline
\end{tabular}

Table 2. Tensile properties of the CTWIP steel as a function of the strain rate.

Both the yield and the tensile strength of the CTWIP steel generally show small variations with the strain rate; in particular, the tensile strength sensibly decreases by increasing the strain rate.

A high work-hardening rate is maintained during the whole test; this behavior was previously noted in high-Mn steels and attributed to mechanical twins acting as obstacles for gliding dislocations $[1,2]$.

The engineering stress-strain curves of the CTWIP are plotted in Fig. 2. These curves show the different plastic behavior of the steel as a function of the strain rate.

The Plastic Localization (PL) phenomena start at larger and larger strains $\left(\varepsilon_{\mathrm{PL}}\right)$ as the strain rate increases, which is consistent with a dynamic strain aging mechanism. No PL effects were detected in the tensile test carried out with $40 \mathrm{~mm} / \mathrm{s}$ cross-head displacement control $\left(0.27-0.57 \mathrm{~s}^{-1}\right.$ strain rate).

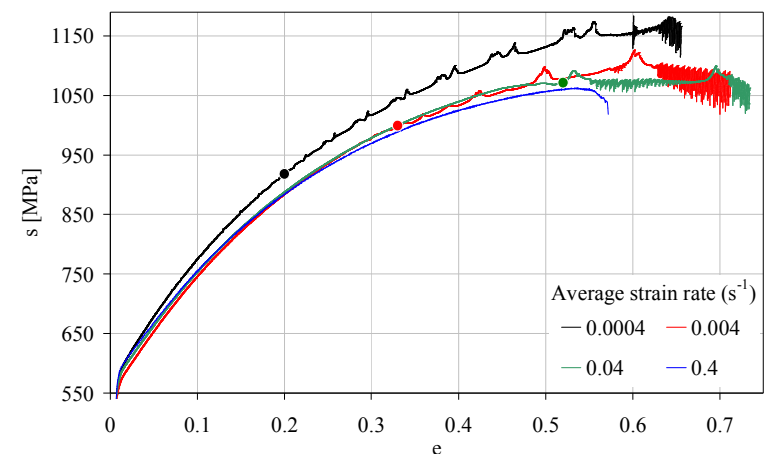

Fig. 2. Engineering stress-strain curves (strain calculated from cross-head displacement) and onset of the PL effect $(\bullet)$ as a function of strain rate. No PL effect for the $0.4 \mathrm{~s}^{-1}$ strain rate 
Between 0.2 and 0.55 engineering strain (depending on the strain rate, Fig. 2), successive macroscopic type I deformation bands (forming about $60^{\circ}$ angles with the tensile axis and involving the full specimen width) travel along the specimen, a new one being nucleated as the previous reaches one of the specimen heads, while the gage displacement vs. stress curve shows a series of steps, each corresponding to the transit of a band through the gage length (Fig. 3), and the crosshead displacement vs. stress curve shows isolated stress peaks, each immediately preceding the nucleation of a new band (Fig. 2). Afterwards, and up to rupture, a series of type II stationary deformation bands appears, giving off distinctive noise, forming about $45^{\circ}$ angles with the tensile axis, most being immediately adjacent to the preceding ones, while the stress vs. strain curve shows a series of serrations with large stress drops (Fig. 4).

As the strain rate is increased from 0.0004 to $0.4 \mathrm{~s}^{-1}$, the overall flow stress slightly decreases, and $\mathrm{A}$ bands occur only at a larger strain (increasing $\varepsilon_{\mathrm{PL}}$ ) and travel faster throughout the tensile samples.

The typical shapes of the stress-strain curves, recorded by the use of a $25 \mathrm{~mm}$ gage extensometer, in the strain range where type I bands appear, is displayed in Fig. 3a. Short intervals of plastic strain at almost constant stress are evident: when a type I band crosses the gage measurement zone (Fig. 3b) a plateau origins in the engineering stress strain curve; after that, the stress increases (with an almost elastic slope), until a successive type I band travels through the gage zone, repeating the same flow stress behavior.

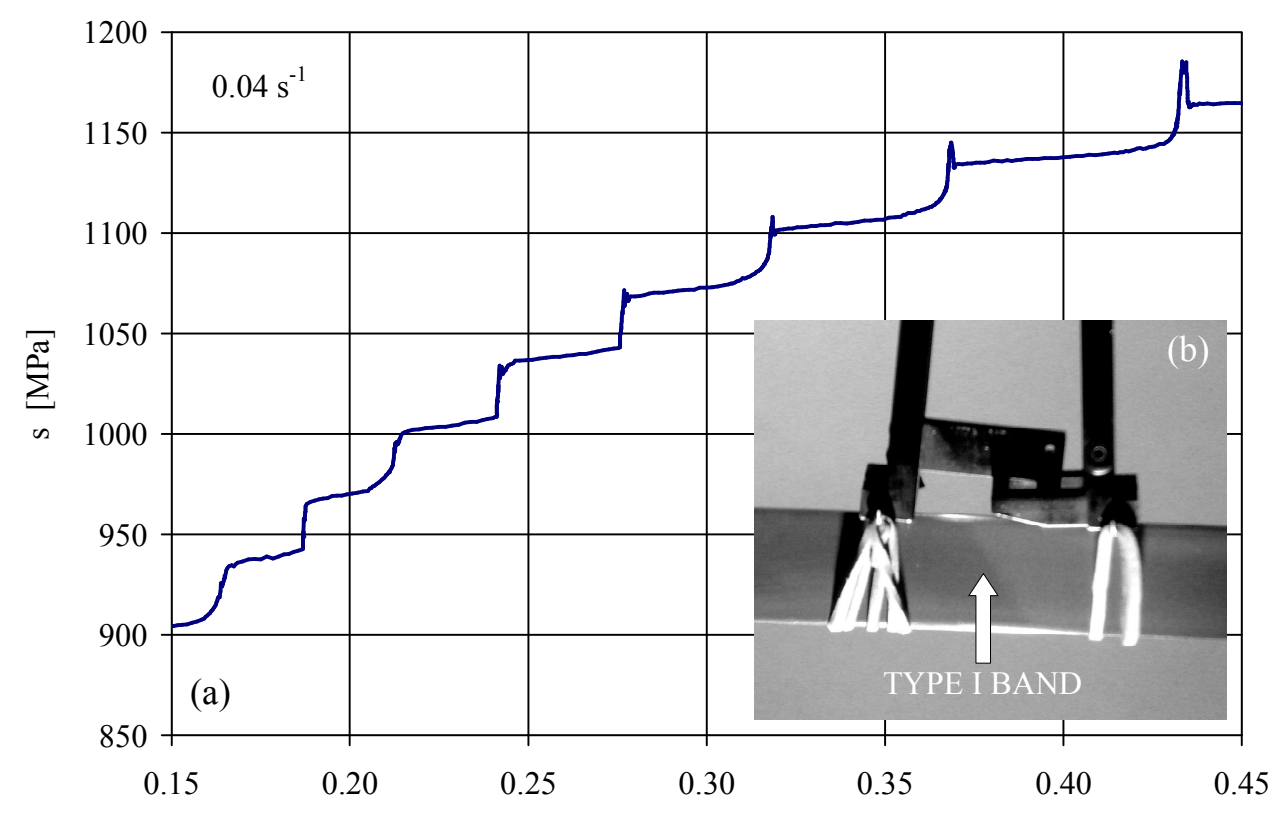

Fig. 3. Effect of the type A serrations in the engineering stress-strain curve (a). Type A band in the gage measurement zone (b). Strain calculated from the gage displacement.

Some stress-strain curves, during the occurrence of type $\mathrm{C}$ bands, are displayed in Fig. 4a. In this case, no strain gage was mounted and the sample strain was detected by means of the cross-head displacement sensor. When a $\mathrm{C}$ band appears, the tensile stress suddenly drops at almost constant strain in order to maintain a constant cross head speed during the test. The same $\mathrm{C}$ bands are evident on tensile specimens as crossed macroscopic deformation bands (Fig. 4b), defined as $\alpha$ or $\beta$ characteristics by Chakrabarti and Spretnak [8]. 


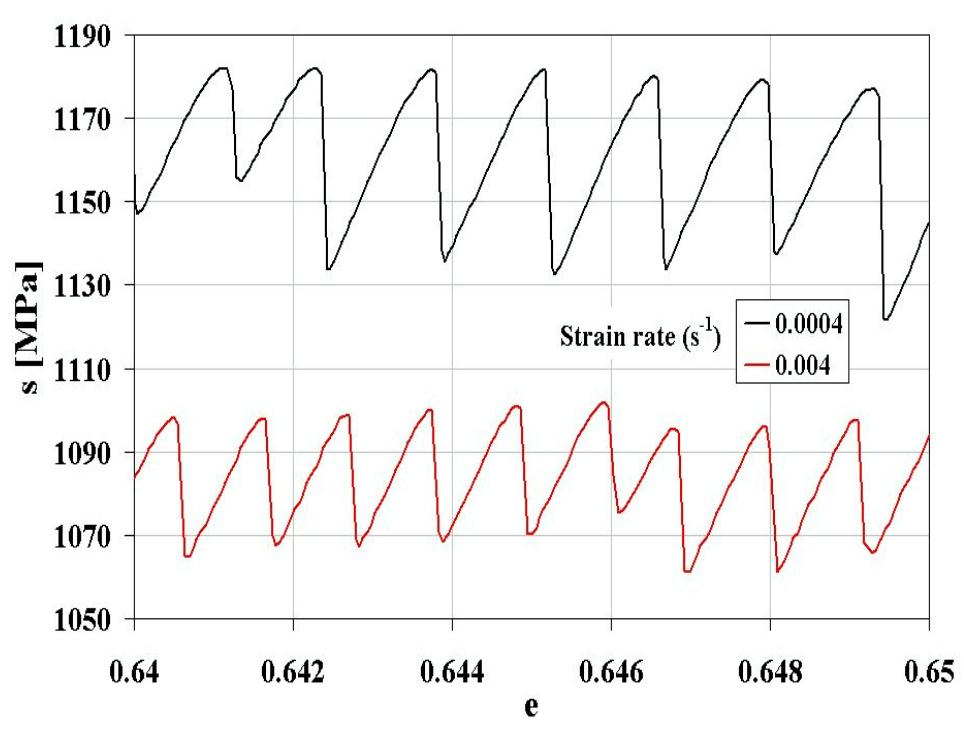

(a)

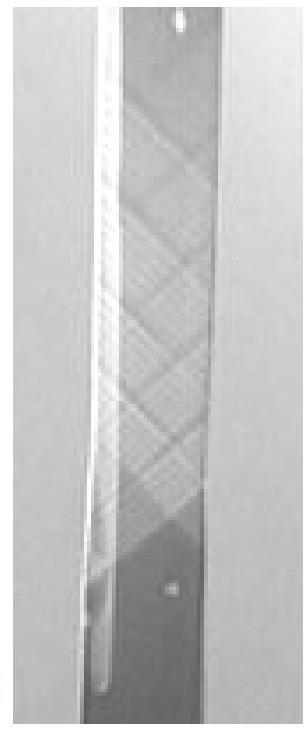

(b)

Fig. 4. Effect of the type $\mathrm{C}$ serrations in the engineering stress-strain curve (a). Type $\mathrm{C}$ bands on the tensile specimen. Strain calculated from the cross-head displacement.

The amplitude of the stress drops induced by the $\mathrm{C}$ type instabilities overall increases with the strain rate (during each test).

The increase of the stress drop amplitude with increasing strain can be explained by hypothesizing that the DSA becomes more effective because the increasing twin density (due to the increasing strain) implies a shorter dislocation mean free path, that leads to an earlier recapture and pinning of the mobile dislocations [9].

The final fracture was almost orthogonal to the tensile axis in the specimens tested with the lowest strain rate, whereas at 0.004 and $0.04 \mathrm{~s}^{-1}$ strain rate it occurred mostly at an angle of approximately $45^{\circ}$ to the tensile axis, with a small central orthogonal fracture zone at the higher strain rate (Fig. 5). Orthogonal fractures can be explained by the collapse of the $\alpha$ or $\beta$ characteristic bands into a single orthogonal feature at the moment of rupture.
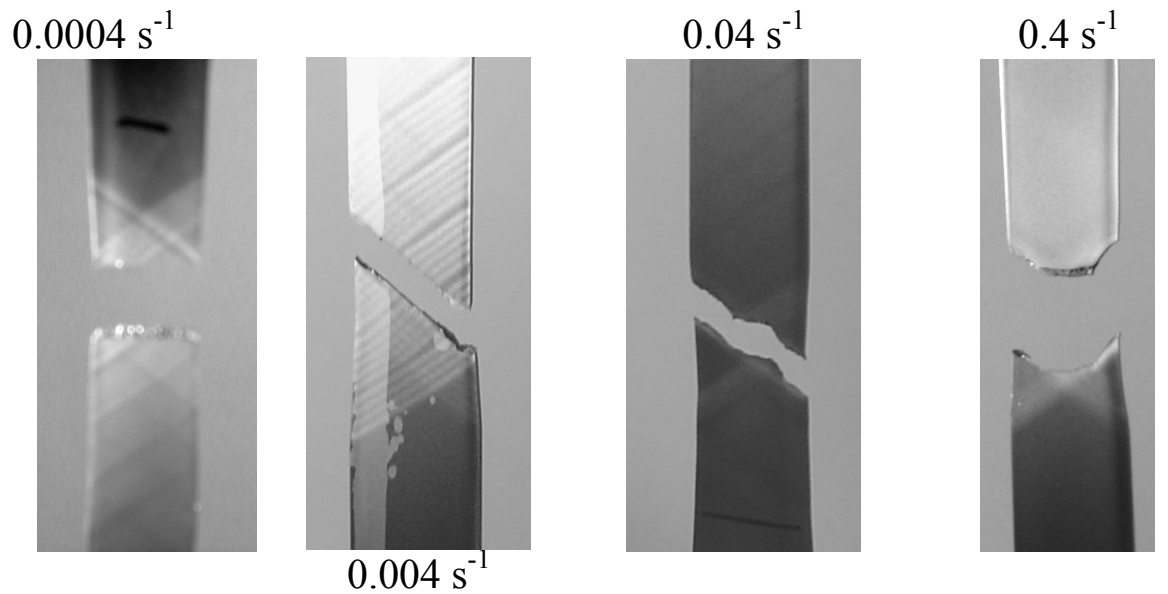

Fig. 5. Macroscopic fracture shape as a function of the strain rate.

The fracture surfaces are completely ductile (neither cleavage nor intergranular rupture are present) with very small dimples, consistent with the fine microstructure of the as-received steel. 
The fracture surface doesn't change within the examined tensile tests strain rate.

On the previously polished specimen surfaces, the SEM analysis (Fig. 6) showed sets of parallel surface steps, their development being limited to each single grain and therefore by the deformed austenite grain boundaries, with spacing of tenths of $\mu \mathrm{m}$; by comparison with previous results $[1,2,10]$, these are due to the intersection of twin planes with the specimen surface.

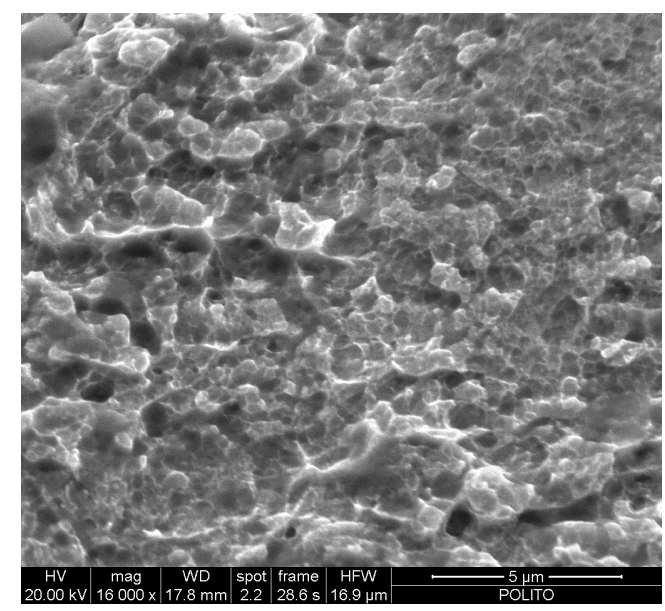

a)

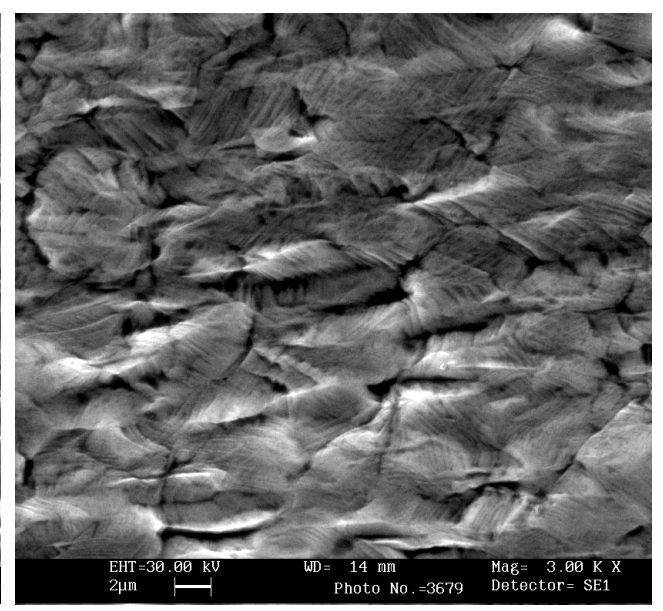

b)

Fig. 6. SEM Analysis. Tensile fracture surface (a) and twinning deformation surface steps on the previously polished surface (b).

The X-ray diffraction analysis revealed that neither bct-martensite nor hcp-martensite were formed, since no peaks amenable to them were detected; this is consistent with the stacking fault energy of the CTWIP (about $20 \mathrm{~mJ} \mathrm{~mol}^{-1}$ [5]), that is too high to cause martensitic transformation in the deformed austenite. On the other hand, both the intensity and the width of the peaks are slightly changed, probably due to the re-orientation of the austenite crystal structure.

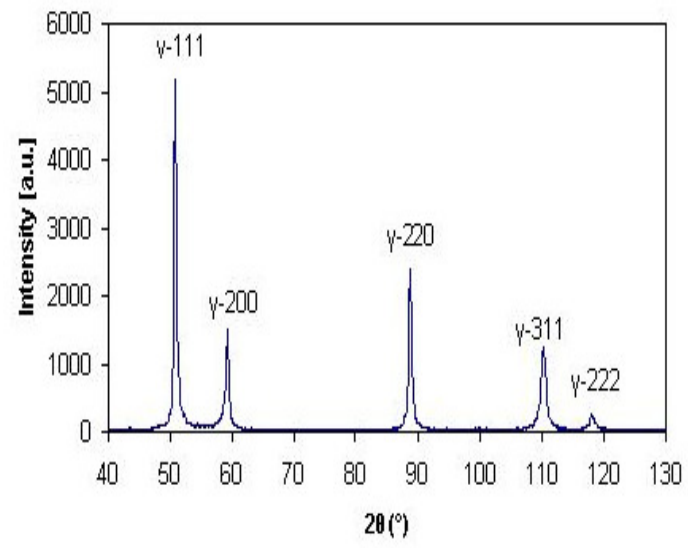

(a)

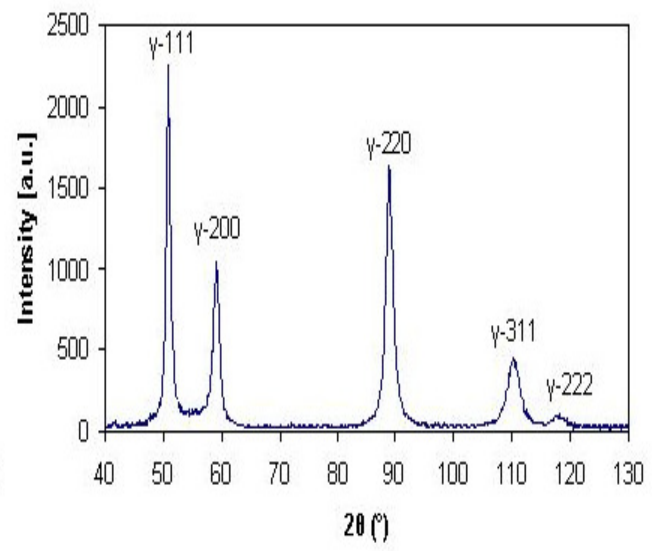

(b)

Fig. 7. Diffractograms of the CTWIP steel before (a) and after (b) tensile tests. Co $\mathrm{K}_{\alpha}$ radiation.

\section{Discussion}

In the present work, it is noted that the CTWIP steel, if subjected to tensile test in a certain range of strain, strain rate and temperature, shows an irregular plastic flow as a consequence of a material instability (inhomogeneous deformation). This behavior was previously observed in other alloys, it was referred to as 'serrated flow' or 'repetitive yielding' or 'jerky flow', and has been often attributed to the Portevin - Le Chatelier (PLC) effect [11]. 
The unsTab. plastic flow triggered during tensile deformation in the PLC range goes along with inhomogeneous deformation of the specimen as the plastic strains localize in bands which may be stationary (type $\mathrm{C}$ bands) or travel along the tensile axis, either through the whole specimen length (type A bands) or only through part of it (type B bands). The unsTab. plastic flow is basically traced back to a negative strain rate sensitivity of the flow stress, namely a decrease of the flow stress with increasing applied strain rate, while the global stress-strain curve still displays positive strain hardening [12].

Such an anomalous behavior may be induced by Dynamic Strain Aging (DSA), which refers to the effect that, during the waiting time spent at obstacles, glide dislocations are subjected to an additional pinning by solute atoms diffusing towards the dislocations, such that the obstacle strength increases as the waiting times increase. As smaller waiting times correspond to larger average dislocation glide velocities and macroscopic strain rates, an inverse rate sensitivity of the flow stress may arise (strain-rate softening) [12].

Both the overall negative strain rate sensitivity of the CTWIP steel, and the nature of the type I and type II plastic localization (PL) bands during the tensile tests performed at $0.04 \mathrm{~s}^{-1}$ or lower strain rate, in the same steel, as described above, are consistent with the occurrence of a PLC effect in the CTWIP steel; in this regard, the type I and type II plastic localization (PL) bands noted above are recognized as type A and type C PLC bands. Type B deformation bands were not clearly detected, but may also have been present during the transition between type $\mathrm{A}$ and $\mathrm{C}$ bands in the above described CTWIP steel tensile tests.

Since the strain localization associated with the PLC effect is repetitive (as opposed to the Lüders bands, which occur only at first yield), it cannot be suppressed by pre-deformation (skin pass), and so surface markings and waviness of aesthetic concern may be induced by the plastic inhomogeneities during sheet forming operations.

\section{Conclusion}

The appearance sequence of the various PLC type bands is determined by a complex interplay of DSA kinetics and dislocations that, in the present case, is further complicated by the existence of twinning mechanisms.

The plastic instability affects the plastic behavior, and in turn, the mechanical behavior of the CTWIP steel. This is related with the decreasing of tensile strength with strain rate, referred to as negative strain rate sensitivity. However the contribution of the PLC effect to the total elongation (ductility) is only qualitatively understood and the recent results from the literature are rather limited.

The PLC phenomenon disappears as the cross head speed becomes quite high (cross head speed $40 \mathrm{~mm} / \mathrm{s}$, strain rate $0.27-0.57 \mathrm{~s}^{-1}$ ). Further tensile tests will be necessary in order to define the exact threshold strain rate above which PLC effect disappears; from the present results, it is possible to conclude that in the present steel such a threshold is comprised in the 0.04 to $0.4 \mathrm{~s}^{-1}$ range.

The tensile tests demonstrate that high manganese medium carbon steels are characterized by high strength-ductility combinations even at high strain rates. These beneficial properties are a consequence of the interaction between twinning induced plasticity and dislocation sliding.

The dynamic strain aging is hypothesized to be the primary mechanism inducing the PLC effect in this alloy, although the exact nature of the interaction between mobile dislocations and carbon atoms is still controversial and other mechanisms causing PLC effects are proposed in the literature $[13,14]$.

\section{Acknowledgements}

Steel procurement by Fiat Auto and ArcelorMittal steelwork are gratefully acknowledgement. Thanks are due to PhD student Chiara Pozzi of the Politecnico di Torino for X-ray analysis. 


\section{References}

[1] O. Grässel and G. Frommeyer: Mat. Science and Tech. Vol.14 (1998), p. 1213-1216.

[2] O. Grässel, L. Kruger, G. Frommeyer and L. W. Meyer: Int. J. of Plast. Vol. 16 (2000), p. 1391.

[3] P. Yang, Q. Xie, L. H. Meng, Ding and Z. Tang: Scripta Materialia Vol. 55 (2006), p. 629.

[4] S. Vercammen, B. Blanpain, B. C. D. Cooman and P. Wollants: Acta Metall. Vol. 52 (2004), p. 2005.

[5] O. Bouaziz and N. Guelton: Mat. Science and Eng. A Vol. 319-321 (2001), p. 246.

[6] S. Allain, J. P.Chateau and O. Bouaziz: Mat. Science and Eng. A vol. 387-389 (2004), p. 143.

[7] ASTM E112-96, Standard Test Methods for Determining Average Grain Size (international standard, ASTM, 1996).

[8] A.K. Chakrabarti and J.W. Spretnak: J. Met. Mat. Trans. A vol.6 (1975), p. 733.

[9] Y. Estrin and L.P. Kubin: Cont. Mod. for Mat. with Micr. Ed. Muhlhaus New [10]York: Wiley (1995), p. 395.

[11] H. Ding and Z.Y. W.Tang: Li et al., J. of Iron and Steel Res., Inter. (2006), vol. 13(6), p. 66.

[12] A. Portevin and F. Le Chatelier: Sur un phénomène observè lors de l'essai de traction d'alliages encours de transformation. Comptes Rendus de l'Académie des Sciences Vol. 176 (1923), p. 507.

[13] E. Rizzi, P. Häner: Inter. J. of Plast. Vol. 20 (2004), p. 121.

[14] Y.N. Dastur, W.C. Leslie: Met. Trans. (1981), vol.12, p. 749.

[15] W.S. Owen, M. Grujicic: Acta Mater. (1999), vol. 47, p. 111. 